\title{
Enfoque criminológico de las migraciones, de Elisa García España, Síntesis, 2018
}

\author{
Por: Cristina Fernández Bessa \\ Universidade da Coruña
}

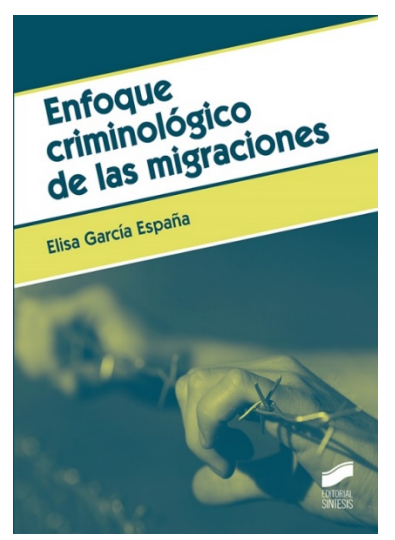

Enfoque criminológico de las migraciones es el último libro de Elisa García España, profesora de la Universidad de Málaga y directora del Observatorio criminológico del sistema penal ante la inmigración (OSCPI). Se trata de una guía didáctica que pretende cuestionar la relación entre inmigración y delincuencia a partir de los conocimientos científicos de la criminología. La obra ha sido publicada por la editorial Síntesis y está disponible en papel y en formato electrónico. Se organiza en 10 capítulos breves, en los que, siguiendo la secuencia lógica de un trabajo de investigación, se proporcionan las definiciones, teorías y datos necesarios para que quien se aproxima por primera vez al tema comprenda sus especificidades.

Recientemente, el tema de las migraciones, la respuesta del sistema de justicia penal ante estas, el control de fronteras y la criminalidad relacionada con la movilidad internacional, bajo la denominación de "criminología de la movilidad" (Aas y Bosworth, 2013, Pickering et al, 2018), se han convertido en uno de los temas más prolíficos de la criminología a nivel internacional. En nuestro país, Elisa García España, pionera en el análisis de la delincuencia de la inmigración en España (véase, García España, 2001), a lo largo de su carrera ha hecho una labor más que encomiable situando la criminalización, el

Revista Española de Investigación Criminológica

Recensión 3, Número 17 (2019)

https://doi.org/10.46381/reic.v17i0.295

www.criminologia.net

ISSN: 1696-9219 
control y la gestión penal de la inmigración como un tema de necesario enfoque criminológico, y con esta obra ha puesto esta perspectiva al alcance de muchos.

El libro está dirigido a lectores con (o en proceso de) formación criminológica, pero su estilo claro, didáctico y divulgativo la convierten en una herramienta útil también para personas que, sin ser expertas, estén interesadas y quieran aproximarse a este tema con rigor (periodistas, profesionales o personas voluntarias del ámbito social, de la política, etc.).

A modo de introducción, en los dos primeros capítulos se construye sociológicamente el objeto de estudio: la relación de la inmigración con la delincuencia y las políticas de seguridad, y se explicita la posición epistemológica (p.20). Para ello, tras una breve contextualización de las migraciones internacionales y su tratamiento en Europa, casi a modo de glosario, se define gran parte de la terminología empleada a lo largo del libro (extranjeros, inmigrantes, minorías étnicas, estereotipos, etc.). Es de especial relevancia para la comprensión del resto de capítulos la descripción de los sesgos cognitivos más extendidos en relación con la inmigración (p.25 y ss.), y sus efectos sobre las opiniones de la ciudadanía, sus actitudes punitivas y sus repercusiones en las decisiones político-criminales.

En el capítulo tres nos encontramos con la metodología y la presentación del estado del arte. En este apartado, se indican algunas cautelas para tener en cuenta respecto al uso de fuentes secundarias para investigar sobre el tema, y los pros y contras del uso de estadísticas policiales, judiciales y penitenciarias sobre inmigración y delincuencia. También se muestran otras formas (menos extendidas) de acercarse al objeto de estudio: autoinformes, expedientes oficiales del sistema de justicia penal, entrevistas cualitativas u observación directa. Más adelante, se expone un conjunto de estudios empíricos que a lo largo del siglo XX y XXI han abordado la relación entre inmigración y delincuencia, subrayando los sesgos cognitivos, ideas estereotipadas y prejuicios que en ocasiones han permeado estas investigaciones (p.52 y ss.). Como conclusión del capítulo se afirma de forma rotunda que no existe una relación causal entre inmigración y delincuencia (p.59) y que, tal como se demuestra en los estudios expuestos, en caso de encontrar una participación delictiva de los inmigrantes superior a la de los autóctonos, no se debe buscar la explicación en cuestiones culturales o aspectos relacionados con el proceso migratorio, sino en el contexto de acogida. La superación de la

\section{Revista Española de Investigación Criminológica}

Recensión 3, Número 17 (2019)

https://doi.org/10.46381/reic.v17i0.295

www.criminologia.net

ISSN: 1696-9219 
búsqueda de la causalidad de la relación ha sido lo que, según la autora, ha permitido que la investigación criminológica reciente se enfoque en la prevención, tal como se muestra en el último capítulo, centrándose en los factores de riego y de protección del contexto social de acogida.

El marco teórico se desarrolla en los capítulos cuatro y cinco. En el primero se expone un interesante recorrido sobre cómo se ha explicado la delincuencia cometida por inmigrantes a lo largo de la historia del pensamiento criminológico desde una perspectiva determinista, según teorías basadas en las variables personales, el conflicto cultural, la desorganización social y la oportunidad diferencial (p.61-77). Desde una perspectiva plenamente conflictualista, en el capítulo cinco se pone el acento en el estudio de la delincuencia registrada, tomando como referencia las teorías del etiquetamiento y el control social (p.7984) y se presentan los sesgos étnicos del sistema judicial demostrados por estudios empíricos (p.84-89). Como evolución de tal perspectiva, este capítulo describe las principales características de la teoría de la justicia procedimental (p.89), utilizada recientemente en relación con los controles policiales, y presenta algunas investigaciones empíricas que la toman como referencia y tratan de verificarla.

En el capítulo seis encontramos el estado de la cuestión según los últimos datos de los registros oficiales de la delincuencia de inmigrantes (p.102 y ss.) y, además, se describen con detalle las distintas bases de datos disponibles (policiales, judiciales y penitenciarias, internacionales y españolas), sus fuentes y variables (p.95-102).

A continuación, se detallan algunas tipologías delictivas relacionadas con la inmigración. En concreto, en el capítulo siete se tratan manifestaciones de la delincuencia común relacionadas con la criminalización de actividades de subsistencia -como el llamado top manta (p.112), y el riesgo delictivo de algunos menores extranjeros no acompañados (p.114)-, la violencia de género -en que los migrantes son tanto víctimas como victimarios (p.118)- y la delincuencia motivada culturalmente -como la mutilación genital femenina (p.122). En el capítulo ocho se aborda la delincuencia organizada relacionada con la inmigración; para ello se examina la ineludible distinción entre tráfico de inmigrantes (smuggling) y trata (traffficking), que tantas confusiones produce en su regulación, en su

Revista Española de Investigación Criminológica

Recensión 3, Número 17 (2019)

https://doi.org/10.46381/reic.v17i0.295

www.criminologia.net

ISSN: 1696-9219 
persecución y, por lo tanto, en la protección de sus víctimas (p.127-128). También produce confusión la relación de estas situaciones con la criminalidad organizada y la inmigración. Por un lado, porque lo relevante para que exista una situación de trata son los fines de explotación -como el sexual (p.133 y ss.)-, independientemente de la situación migratoria de sus víctimas y de que se produzca o no el cruce de fronteras. Por el otro, la configuración del delito de tráfico de inmigrantes también es controvertida. Como muestra el libro en relación con el caso americano, según algunas investigaciones empíricas, "para los inmigrantes, los traficantes son esencialmente actores de buena fe que prestan un servicio imprescindible de cara a conseguir el destino migratorio" (p.131). En el caso europeo, la reciente persecución y criminalización de personas solidarias y oenegés dedicadas a rescatar inmigrantes en el Mediterráneo pone seriamente en cuestión la legitimidad de esta modalidad delictiva que ilegaliza cualquier ayuda o favorecimiento de la llamada inmigración irregular, incluso si es con fines humanitarios.

En el capítulo 9 se analiza la respuesta del sistema penal ante el control migratorio. Para ello García España nos acerca a la llamada crimmigration (Stumpf, 2006) y la traduce al español como "crimigración" (p.143), un concepto cada vez más utilizado en el debate internacional para referirse al uso de medidas excepcionales contra los inmigrantes y a las interferencias entre el derecho penal y la normativa de extranjería. La expulsión de los extranjeros sospechosos de haber cometido un delito (artículo 57.7 de la Ley Orgánica de Extranjería -LOEX), las distintas posibilidades de expulsión de personas extranjeras condenadas (artículo 89 del Código Penal), o la expulsión por haber sido condenado a una pena de más de un año de prisión (artículo 57.2 de la LOEX), que se convierte en el impedimento de cualquier posibilidad de reinserción social, son algunos de los ejemplos más significativos de la crimigración en España que se exponen en el libro (p.146-153). Además, este capítulo también trata dos temas de gran actualidad: la falacia de las expulsiones cualificadas (p.154-155), un invento del Ministerio de interior para legitimar las expulsiones vinculándolas a la criminalidad y la reincidencia (Fernández Bessa \& Brandariz García, 2016), y los controvertidos centros de internamiento de extranjeros (CIE), denunciados en múltiples ocasiones por las vulneraciones de derechos que comportan que, además, son

\section{Revista Española de Investigación Criminológica}

Recensión 3, Número 17 (2019)

https://doi.org/10.46381/reic.v17i0.295

www.criminologia.net

ISSN: 1696-9219 
ineficaces en relación con la expulsión, ya que en el 50\% de los casos el internamiento no conduce a la ejecución de la deportación (p.155-157).

Finalmente, en el último capítulo se plantean distintas estrategias de intervención (primaria, secundaria y terciaria), ofreciéndose una vertiente eminentemente práctica de este enfoque. En concreto, se aportan ejemplos de prevención cuando los migrantes pueden ser víctimas -de trata con fines de explotación sexual (p.168-170)- o autores -menores extranjeros no acompañados (p.165-168)- de delitos, así como estrategias dirigidas a evitar el etiquetamiento de los inmigrantes como delincuentes ante los controles policiales -en actuaciones de identificación por perfil étnico (p.170-172).

En síntesis, este libro constituye una aproximación muy sólida para ubicarse en las discusiones nacionales e internacionales sobre la materia. Sin duda es una ventana para asomarse a una gran variedad de temas, teorías y herramientas metodológicas para comprender la relación entre inmigración y delincuencia, que suscita a quien lo lee el interés por seguir profundizando. La experiencia y contacto directo de la autora con la realidad de las personas migrantes proporciona a la obra una gran riqueza y variedad de ejemplos, que sin duda hacen que su lectura sea ágil, amena y accesible.

Enfoque criminológico de las migraciones muestra múltiples temas de gran relevancia para comprender la penalidad contemporánea. Hoy en día la sociedad española es multiétnica y multinacional y ello plantea retos criminológicos que se tratan en este libro. Por ejemplo, la relación entre etnicidad y selectividad policial; las implicaciones de la nacionalidad y la situación de residencia en la respuesta del sistema punitivo; el riesgo delictivo de determinadas sociedades de acogida, etc. En mi experiencia como profesora en varios grados y másters de criminología, estaba echando en falta unos materiales de este tipo, cuya selección de temas y estructura son de gran utilidad para elaborar un plan docente.

Su breve extensión hace que la obra sea muy manejable, pero también supone que a pesar de la variedad de fuentes y aproximaciones multidisciplinares que proporciona la autora, algunos temas sean tratados de forma somera. De hecho, una de las aportaciones más destacables y útiles de este libro es la completa revisión de las teorías criminológicas desde las que se ha tratado la criminalidad y la criminalización de la inmigración y de los estudios

\section{Revista Española de Investigación Criminológica}

Recensión 3, Número 17 (2019)

https://doi.org/10.46381/reic.v17i0.295

www.criminologia.net

ISSN: 1696-9219 
actuales que las contrastan. Es aquí donde también se encuentra la mayor carencia de esta edición. Por una incomprensible política editorial que pretende "poner en aplicación unos principios ecológicos, económicos y prácticos" (p.181), las referencias bibliográficas se encuentran en la página web de la editorial, no en el libro (tampoco en el formato electrónico ${ }^{1}$ ). Dada la finalidad didáctica de esta obra, se echa en falta que la bibliografía esté en el mismo soporte que el texto, así como una mayor sistematicidad y equilibrio en el tratamiento de los distintos capítulos, sobre todo en cuanto a la centralidad o accesoriedad de los ejemplos o estudios de caso.

Este libro, único en lengua castellana que plantea el estudio de las migraciones desde una perspectiva criminológica, supone un gran avance en la materia y proporciona una amplia caja de herramientas para estudiantes e investigadores. Desde el principio la obra aboga por superar el binomio inmigración-criminalidad y todos sus capítulos se articulan a partir de este eje. Esta contribución abona el terreno del campo de estudio para que otros trabajos vayan más allá y desarrollen investigaciones sobre otros temas relacionados con las migraciones (como, por ejemplo, la proliferación del racismo y la xenofobia, los llamados delitos de solidaridad, la relación entre el asilo y el control migratorio, etc.) desde un enfoque declaradamente criminológico. Dicho de otro modo, investigaciones que trasciendan la crimigración y que desde la "criminología de la movilidad" (Pickering, et al. 2018) se centren en las interacciones derivadas del régimen de fronteras, el control migratorio, así como las repercusiones del origen étnico o nacional en las pautas de funcionamiento del sistema de control, los comportamientos desviados y su prevención.

\section{Referencias bibliográficas}

\footnotetext{
${ }^{1}$ Sobre este formato, lamento decir que su manejo no es demasiado funcional. Por un lado, independientemente del dispositivo que se utilice, las páginas tan solo se visualizan enteras tal como están editadas en papel, sin la posibilidad de adaptar el tamaño de la letra a la pantalla para facilitar su lectura. Por otro lado, la interactividad es bastante limitada, ya que no permite introducir anotaciones, no es fácil subrayar, y no permite seleccionar el texto y copiarlo, ni tampoco imprimirlo. Tratándose de materiales didácticos, estas limitaciones dificultan su uso para el estudio, así que, por la escasa diferencia de precio, recomendaría la versión en papel.
}

Revista Española de Investigación Criminológica

Recensión 3, Número 17 (2019)

https://doi.org/10.46381/reic.v17i0.295

www.criminologia.net

ISSN: 1696-9219 
Aas, Katja Franko y Bosworth, Mary (eds.) The Borders of Punishment: Migration, Citizenship, and Social Exclusion. Oxford: Oxford University Press. 2013.

Fernández Bessa, Cristina y Brandariz García, José A. «Transformaciones de la penalidad migratoria en el contexto de la crisis económica: El giro gerencial del dispositivo de deportación», InDret, 4 (2016), p. 1-25.

García España, Elisa. Inmigración y delincuencia en España: análisis criminológico. Valencia: Tirant lo Blanch, 2001.

Pickering, Sharon et al. «The criminology of mobility», en: Pickering, Sharon y Ham, Julie (eds.) The Routledge handbook on crime and international migration. New York: Routledge, Taylor \& Francis Group, 2018, p. 382-395.

Stumpf, Juliet. «The Crimmigration crisis: Immigrants, crime, and sovereign power». American University Law Review, 56 (2) (2006), p. 367-419.

Recensión 3, Número 17 (2019)

https://doi.org/10.46381/reic.v17i0.295

www.criminologia.net

ISSN: 1696-9219 